\title{
Distraction by a cognitive task has a higher impact on electrophysiological measures compared with conditioned pain modulation
}

\author{
A. T. L. Do ${ }^{1 \dagger}$, E. K. Enax-Krumova ${ }^{1 *+} \oplus$, Ö. Özgül ${ }^{1}$, L. B. Eitner ${ }^{2,3}$, S. Heba', M. Tegenthoff, C. Maier ${ }^{2}$ and O. Höffken ${ }^{1}$
}

\begin{abstract}
Background: Conditioned pain modulation (CPM) evaluates the effect of a painful conditioning stimulus (CS) on a painful test stimulus (TS). Using painful cutaneous electrical stimulation (PCES) as TS and painful cold water as CS, the pain relief was paralleled by a decrease in evoked potentials (PCES-EPs). We now aimed to compare the effect of CPM with cognitive distraction on PCES-induced pain and PCES-EP amplitudes.

Methods: PCES was performed using surface electrodes inducing a painful sensation of 60 (NRS 0-100) on one hand. In a crossover design healthy subjects (included: $n=38$, analyzed: $n=23$ ) immersed the contralateral hand into $10^{\circ} \mathrm{C}$ cold water (CS) for CPM evaluation and performed the 1-back task for cognitive distraction. Before and during the CS and 1-back task, respectively, subjects rated the pain intensity of PCES and simultaneously cortical evoked potentials were recorded.

Results: Both CPM and cognitive distraction significantly reduced PCES-EP amplitudes (CPM: $27.6 \pm 12.0 \mu \mathrm{V}$ to $20.2 \pm 9.5 \mu \mathrm{V}$, cognitive distraction: $30.3 \pm 14.2 \mu \mathrm{V}$ to $13.6 \pm 5.2 \mu \mathrm{V}, \mathrm{p}<0.001$ ) and PCES-induced pain (on a $0-100$ numerical rating scale: CPM: $58 \pm 4$ to $41.1 \pm 12.3$, cognitive distraction: $58.3 \pm 4.4$ to $38.0 \pm 13.0, p<0.001$ ), though the changes in pain intensity and PCES-amplitude did not correlate. The changes of the PCES-EP amplitudes during cognitive distraction were more pronounced than during CPM $(p=0.001)$.

Conclusions: CPM and cognitive distraction reduced the PCES-induced pain to a similar extent. The more pronounced decrease of PCES-EP amplitudes after distraction by a cognitive task implies that both conditions might not represent the general pain modulatory capacity of individuals, but may underlie different neuronal mechanisms with the final common pathway of perceived pain reduction.
\end{abstract}

Keywords: Painful cutaneous electrical stimulation, Conditioned pain modulation, Cognitive distraction, Pain mechanisms

\section{Background}

The processing of nociceptive information is modulated by different endogenous mechanisms, which can be antinociceptive or pronociceptive $[1,2]$. The conditioned

\footnotetext{
*Correspondence: elena.krumova@rub.de

${ }^{\dagger}$ A. T. L. Do and E. K. Enax-Krumova contributed equally to this manuscript

${ }^{1}$ Department of Neurology, Ruhr-University Bochum, BG University

Hospital Bergmannsheil gGmbH, Bürkle-de-la-Camp-Platz 1,

44789 Bochum, Germany

Full list of author information is available at the end of the article
}

pain modulation (CPM) evaluates the effect of a noxious conditioning stimulus (CS) on a noxious test stimulus (TS), as a surrogate for the function of the descending pain inhibitory pathways $[1,2]$. A pronounced CPMeffect was shown to be inversely related to pain frequency among healthy individuals [3], whereas a reduced CPMeffect has been found in different chronic pain states [4, $5]$ and seems to represent a risk for chronic postoperative pain $[6-8]$.

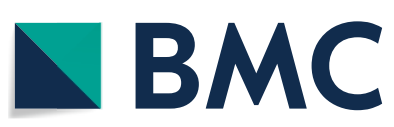

(C) The Author(s) 2020. This article is licensed under a Creative Commons Attribution 4.0 International License, which permits use, sharing, adaptation, distribution and reproduction in any medium or format, as long as you give appropriate credit to the original author(s) and the source, provide a link to the Creative Commons licence, and indicate if changes were made. The images or other third party material in this article are included in the article's Creative Commons licence, unless indicated otherwise in a credit line to the material. If material is not included in the article's Creative Commons licence and your intended use is not permitted by statutory regulation or exceeds the permitted use, you will need to obtain permission directly from the copyright holder. To view a copy of this licence, visit http://creativeco mmons.org/licenses/by/4.0/. The Creative Commons Public Domain Dedication waiver (http://creativecommons.org/publicdomain/ zero/1.0/) applies to the data made available in this article, unless otherwise stated in a credit line to the data. 
Several functional magnetic resonance imaging (fMRI) studies examined the neural mechanism of CPM. Here, cortical and subcortical brain regions are considered to control the descending modulatory pathways [9-12]. Dependent on which stimuli were used for TS and CS, increased MR signal intensities during each TS decreased in presence of CS in brain regions such as the caudal subdivision of the spinal trigeminal nucleus, the region of the subnucleus reticularis dorsalis and the dorsolateral pons near the parabrachial nucleus, the anterior cingulate, orbitofrontal and lateral prefrontal cortices, the amygdala, the primary and secondary somatosensory cortices, supplementary motor area and posterior insula [13-15].

Although CPM has been extensively studied both in animals $[16,17]$ and humans using psychophysiological and electrophysiological methods [18-24], it is still under debate whether the pain reduction during CS results solely from the descending noxious inhibitory pathways. Pain modulation can be achieved also by cognitive factors like attention and distraction [25-27]. Postsurgical pain is reported as more intense when patients are attending to it [28]; in contrast, listening to music [29-31], therapeutic play interventions [32] and animal-assisted treatments [33] for children can reduce postoperative pain intensity, presumably by distraction. Generally, subjects' attention has to be actively directed elsewhere to avoid that painful stimuli prevail over competing non-painful ones [34-37]. Interestingly, both CS and distraction by a cognitive visual task reduced pain intensity of heat stimuli in an additive manner [38].

Data including also objective parameters as readout to compare both pain modulating paradigms are missing. Therefore, we used a CPM paradigm, which we have recently introduced, based on both pain intensity and amplitudes of evoked cortical potentials after painful cutaneous electrical stimulation (PCES-EPs) in healthy subjects by hand immersion in painful cold water as CS [39]. Having an additional objective electrophysiological parameter as readout would make it possible to detect potential differences in signal processing and would also validate the utility of this potential objective biomarker. Hence, we aimed to compare the CPM effect using this paradigm with the pain relief during distraction by a cognitive 1-back task, which is commonly used to assess working memory capacity [34] and was shown to influence pain perception [40-42]. Hereby, we analyzed differences in both subjective pain ratings and objective electrophysiological readouts. Additionally, we examined whether pain intensity of the CS as well as perceived severity grade of the cognitive task and the anger felt about doing a mistake correlated with the changes during both interventions, respectively.

\section{Methods}

Study design and subjects

After approval by the Ethics Committee of the Medical Faculty of the Ruhr University Bochum, Germany (registration nr. 16-5733) 38 healthy subjects (22 females, 16 males, age $22.2 \pm 2.4$ years) were recruited after informed consent. All experiments were performed in accordance with relevant guidelines and regulations. The study was conducted in the Department of Neurology, University Hospital Bergmannsheil Bochum, Germany, between October 2016 and April 2017.

The study was designed as a randomized cross-over study and the subjects were randomized to two groups (Fig. 1a). In group A at first we assessed the CPM and proceeded with the distraction by cognitive task afterwards. For group B, the first intervention was the distraction by cognitive task, and then the assessment of CPM was performed.

Exclusion criteria were insufficient German language skills, pain disorders, nerve injuries, neuropathy and any other neurological disease as well as intake of pain modulating drugs (in the last 2 weeks) or transdermal application of medication (in the last 6 weeks or more than seven days in the last 4 months). Further, we excluded subjects with diagnosis of epilepsy, psychiatric disease and/or circulatory disorders.

During the experiment, the subjects sat in an upright comfortable arm-chair in an air-conditioned room and were instructed to relax and avoid movements, especially of the head and the upper limbs, to prevent artifacts during EEG recording. However, we had to exclude four subjects due to insufficient recording signal caused by electrode malfunction and further eleven subjects because of the absence of enough detectable potentials during the intervention cold water-immersion or performing $n$-back task caused by severe movement artifacts or increased noise in signal processing. After all, we included 23 healthy subjects (10 females, 13 males, age $22.3 \pm 2.7$ years), randomized in two groups: the first included 12 subjects ( 6 females, 6 males, age $21.9 \pm 2.8$ years) and the second one 11 subjects (4 females, 7 males, age $22.8 \pm 2.3$ years).

\section{Painful cutaneous electrical stimulation (PCES)}

For the cutaneous electrical stimulation three planar custom-built concentric electrodes were fixed in a triangular formation on the radial dorsum of the right hand in a distance of 1.5 to $2 \mathrm{~cm}$ to each other. The electrodes were connected in parallel to a stimulator (Digitimer DS7A), thus, the given current intensity was proportionally distributed over all electrodes (for a detailed description see [39]). Each electrical stimulus, applied simultaneously by all three stimulation electrodes, consisted of a train of 


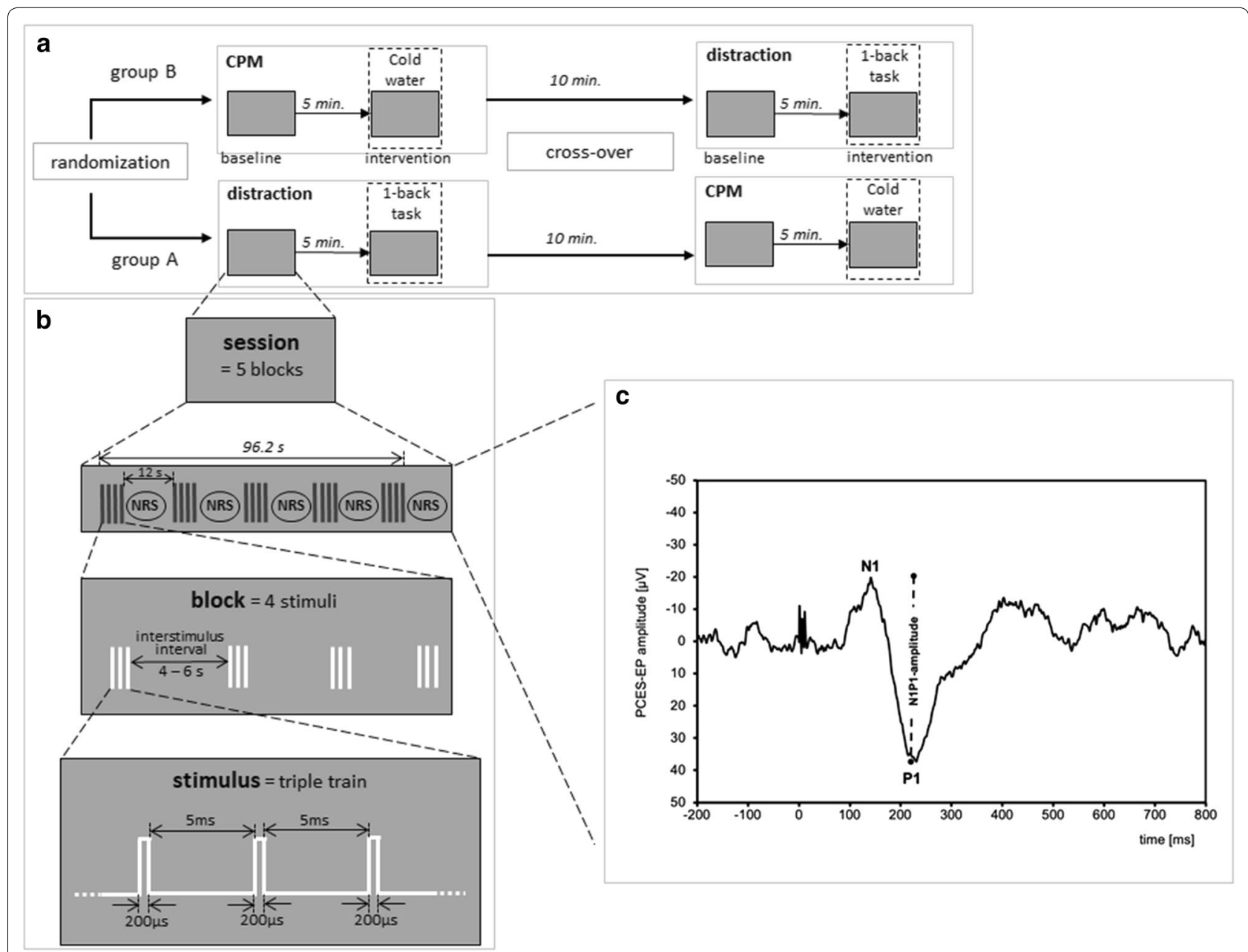

Fig. 1 Study design. a Timeline of experimental procedure, $\mathbf{b}$ paradigm for electrical stimulation and $\mathbf{c}$ evoked potential after painful cutaneous electrical stimulation (PCES-EP) with N1 and P1 peaks recorded over Cz of one subject

three monopolar square waves $(200 \mu \mathrm{s}$ duration, $5 \mathrm{~ms}$ inter-wave interval within the triple train). We applied 20 stimuli in 5 blocks with a variable inter-train interval of $4-5 \mathrm{~s}$ in a pseudo-randomized manner, with a fixed interblock interval of $12 \mathrm{~s}$ (see Fig. 1b). We chose the method of a stable positioning in contrast to shifting between the stimulation parts as this would have led to multiple determination of the necessary stimulus intensity.

First, prior to both interventions we determined the individual detection thresholds (DT) for cutaneous electrical stimuli as well as the corresponding pain thresholds (PT) by increasing current intensities starting with $0.2 \mathrm{~mA}$ steps until the subjects reported a (mostly lightly tingling) sensation (DT) or a pinprick-like pain (PT), respectively. Then we proceeded in $0.1 \mathrm{~mA}$ steps in a randomized order above or below the supposed thresholds until the subjects reported a stable perception.

The stimulation intensity was adjusted to subjects' individual pain intensity corresponding to 60 on the 101-point numerical rating scale (NRS, $0=$ no pain, $100=$ maximum pain imaginable) by increasing the current intensities starting with $0.5 \mathrm{~mA}$ steps and continuing, after subjects rated the pain as 50 , with $0.1 \mathrm{~mA}$ steps.

The effect of the intervention (CPM or distraction, see below) was assessed with stimulation intensity, determined as described above, applying 20 stimuli before and 20 during the intervention (CS and 1-back-task, respectively, see below).

\section{Pain ratings as a subjective readout}

The pain perceived during PCES was reported by the participants after every 4 stimuli $(=1$ block) as a rating on the 101-point numerical rating scale (NRS, $0=$ no pain, $100=$ maximum pain imaginable), resulting in a total of 5 ratings per session (compare Fig. 1). The PCESinduced pain was calculated as mean of the 5 ratings during PCES. 


\section{Cortical potentials as an electrophysiological readout}

Cortical potentials evoked after painful cutaneous electrical stimulation (PCES-EPs) were recorded above $\mathrm{Cz}$ according to the international 10-20 system with reference to linked earlobes (A1-A2), as previously described [39] and stored for offline analysis (Brain Amp, Brain Products, Germany; Bandwith: $1 \mathrm{~Hz}-1 \mathrm{kHz}$; digitization sampling rate: $5 \mathrm{kHz}$ ) (see Fig. 1c). Impedances were kept below $5 \mathrm{k} \Omega$. PCES-EPs were analyzed in sweeps from $200 \mathrm{~ms}$ before and $800 \mathrm{~ms}$ after every stimulus onset using Vision Recorder Version 1.03 as previously described in detail [39]. In accordance with previous studies [37, 43, 44], the first sweep was rejected to avoid bias by initial startling response. After averaging PCESEPs, we analyzed amplitudes of N1-to-P1-peak of PCESEPs (see Fig. 1c). Subjects with recordings with a high artefact overlap due to muscle excitation or loosening of the electrodes were manually identified and excluded.

\section{Intervention}

\section{Conditioned pain modulation (CPM)}

For assessment of the CPM we used PCES on the right hand as TS and immersion of the left hand in cold water as CS. Therefore, subjects immersed their left hand into cold water bath with a temperature of $10{ }^{\circ} \mathrm{C}$, which was controlled immediately before immersion of the hand using a digital thermometer. After $20 \mathrm{~s}$ of CS application, the first PCES started. Subjects dragged out their hand immediately after the last stimulus. Subjects rated the pain intensity induced by the PCES repeatedly on the 101-point NRS after each block (see "Pain ratings as a subjective readout"). Additionally, subjects rated the pain induced by cold water itself, on the 101-point NRS as well.

We calculated the CPM-effect based on the changes of the pain intensity and the PCES-amplitude as follows:

The CPM-effect PAIN $_{\text {was defined as difference }}$ between the mean of five pain ratings during CS and the mean of five pain ratings before CS (baseline).

CPM-effect ${ }_{\text {AMPLITUDE }}$ was calculated as ratio between the amplitude of the averaged PCES-EP during CS and the amplitude of the averaged PCES-EP at baseline.

A difference $<0$ for CPM-effect ${ }_{\text {PAIN }}$ represents an efficient pain inhibition [21, 45]. Analogously, a ratio $<1$ for CPM-effect ${ }_{A M P L I T U D E}$ indicated an efficient pain inhibition.

\section{Distraction by a cognitive task}

For the distraction by a cognitive task we used the well-established 1-back version of the n-back task that requires continuous updating of representations in working memory and response selection [40]. Before starting the 1-back task, subjects were introduced to the test setting. Additionally, instructions were displayed on the screen during the 1-back task. During this task, participants sat in front of a monitor (16-inch diagonal, resolution $1024 \times 768$ pixel) on which a stream of 85 lower-case letters (c, h, k, m, p, s, t, w, y) was presented with a frequency of $1 \mathrm{~Hz}$. The task included 10 target stimuli and 75 nontarget stimuli presented in a random order. The letters appeared one at a time and in white Arial font on a black background in the center of the screen. The size of the letters was $21 \%$ of the monitor height. Each letter was presented for $500 \mathrm{~ms}$, followed by a $500 \mathrm{~ms}$ blank screen. The distance between the subjects' eyes and the monitor was about $95 \mathrm{~cm}$. During presentation of the blank screen, participants were instructed to report whether the letter currently on screen matched the letter presented one letter ago; they indicated their response using two separate foot switches (left foot on foot switch " 1 " for "the current letter was presented 1 letter ago", right one on foot switch " 2 " for "the current letter was not presented 1 letter ago"). Subjects were instructed to use their feet gently enough to avoid movement artifacts, yet strong enough to activate the foot switch. The first letter was displayed on the screen ten seconds before application of the first PCES, and the last letter appeared simultaneously with the last PCES. After every block the stream of letters stopped for 9 to $12 \mathrm{~s}$ so that the participants had time to report the current PCES-induced pain.

Analogous to the CPM assessment, the changes in PCES-induced pain intensity and PCES-evoked cortical potential were calculated each as difference and ratio between the values prior and during the intervention.

After completing the 1-back task, the subjects reported the perceived severity grade of the task and the anger felt while doing a mistake during the task as a rating on an 11 -point numerical rating scale $(0=$ very easy task/no anger, $10=$ very difficult task/very angry).

\section{Statistical analysis}

In order to exclude effects of the randomization sequence (group A and B), in terms of carry-over effect, we have performed a preliminary test, calculating the sum of the values measured in the two interventions for each subject and comparing across the two sequence groups by means of unpaired t-test, according to the experts' recommendations [46]. After exclusion of carry-over effects, we performed repeated measures ANOVA with PCES-induced pain and PCES-EP amplitude as dependent variables, and within-subjects factors "time" (before and during intervention) and "intervention" (CPM and distraction). 
The changes of PCES-induced pain (differences) and PCES-EP-amplitudes (ratios) during CPM and distraction were compared using two-tailed paired t-tests.

Using Pearson correlation analysis, we correlated differences for PCES-induced pain to the ratios for PCES-EP amplitudes during both CPM and cognitive distraction. Additionally, we also correlated the difference for PCES-induced pain and ratios for PCES-amplitudes to the pain intensity rating of the cold water test during CPM session, and to the perceived severity grade of the 1-back task during the distraction, respectively, as well as with the PSQ-score (separately for both CPM and cognitive distraction). Due to the high number of correlations computed $(n=12)$, we adjusted the alpha-level for the correlations analysis using a Bonferroni-correction for multiple comparisons, resulting in a $\mathrm{p}<0.004$ for $\mathrm{a}$ significant correlation.

\section{Results}

\section{Participants and group effects}

Both randomization groups A and B did not differ in their age or gender distribution. After excluding an influence of the group affiliation during randomization (sequence of CPM and distraction as intervention) on both pain intensity and amplitudes of PCES-evoked potentials data from both groups were pooled for all analyses.

\section{Detection threshold, pain threshold and stimulation intensity}

The mean detection threshold for the electrical cutaneous stimulation for perceiving any sensation was at $0.8 \pm 0.2 \mathrm{~mA}$ and the main pain threshold for perceiving a pinprick sensation for the first time was $1.0 \pm 0.3 \mathrm{~mA}$. The mean stimulation intensity to induce a pain intensity corresponding to 60 on the NRS (0-100) was $7.1 \pm 5.3 \mathrm{~mA}$ in the first intervention and $8.0 \pm 5.0 \mathrm{~mA}$ in the second intervention $(\mathrm{p}<0.001)$.

\section{Changes in pain intensity and cortical potentials} during intervention

Group means and standard deviation are reported in Table 1.

\section{Effects of CPM}

During CPM, both PCES-induced pain and PCES-EP amplitude (Fig. 2a, b) significantly decreased during CS application ( $\mathrm{p}<0.001$ for the within factor "time" for both PCES-induced pain intensity and PCES-evoked potentials, Tables 2 and 3 ).

Only one subject showed no CPM-effect PAIN $_{(\Delta}$ $\mathrm{NRS}=0$ ), based on the pain ratings. Four subjects

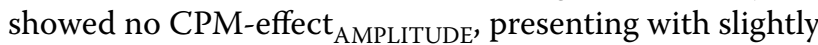
increased amplitudes of PCES-EP during CS application.

The pain intensity of cold water during conditioned pain modulation was rated with $65.2 \pm 20.4$ (range: 20-100) on the NRS (0-100). Pain ratings of the cold water correlated inversely with differences of PCESinduced pain $(\mathrm{r}=-0.44, \mathrm{p}=0.037$, Fig. 3), though a correction for multiple comparisons did not yield a significant result. There was no correlation between the pain ratings of the cold water and the ratios for PCES-EP amplitudes of the CPM intervention at all $(r=-0.069$, $\mathrm{p}=0.766$ ).

The 15 subjects excluded from the further analysis due to artifacts during the PCES-recordings rated the pain intensity induced by the cold water on average significantly more severe compared to the 23 subjects included in the further analysis (NRS $78.0 \pm 10.1$, range 65-100, $\mathrm{p}=0.031$, unpaired $\mathrm{t}$-test).

\section{Effects of distraction}

During distraction, in all subjects both PCES-EP amplitude and PCES-induced pain (Fig. 2a, b) decreased significantly during the 1-back task $(\mathrm{p}<0.001$ for the within factor "time" for both PCES-induced pain intensity and PCES-evoked potentials, Tables 2 and 3).

The perceived severity grade of the task was on average $4.9 \pm 2.0$ and the anger felt about doing a mistake

Table 1 PCES-induced pain ratings and amplitudes of the PCES-evoked potentials as well as effects of the intervention (for pain ratings difference between baseline and during intervention, values $<0$ implicate reduction of the pain rating during intervention; for amplitudes ratios between baseline and during intervention, values $<1$ implicate reduction of the pain rating during intervention)

\begin{tabular}{|c|c|c|c|c|}
\hline & \multicolumn{2}{|c|}{ Conditioned pain modulation } & \multicolumn{2}{|c|}{ Distraction by a cognitive task } \\
\hline & $\begin{array}{l}\text { PCES-EP amplitude }[\mu \mathrm{V}, \\
M W \pm S D \text { (range) }]\end{array}$ & $\begin{array}{l}\text { PCES pain [NRS 0-100, } \\
M W \pm S D \text { (range)] }\end{array}$ & $\begin{array}{l}\text { PCES-EP amplitude }[\mu \mathrm{V}, \\
M W \pm S D \text { (range) }]\end{array}$ & $\begin{array}{l}\text { PCES pain [NRS 0-100, } \\
M W \pm S D \text { (range)] }\end{array}$ \\
\hline At baseline & $27.6 \pm 12.0(8.7 \ldots 57.7)$ & $58.1 \pm 4.5(50 \ldots 72)$ & $30.3 \pm 14.2(18.5 \ldots 84.6)$ & $58.3 \pm 4.4(48 \ldots 66)$ \\
\hline During intervention & $20.2 \pm 9.5(9.4 \ldots .50 .6)$ & $41.1 \pm 12.3(14 \ldots 60)$ & $13.6 \pm 5.2(6.3 \ldots 26.6)$ & $38.0 \pm 13.0(14 \ldots .70)$ \\
\hline Effect & $0.76 \pm 0.23(0.45 \ldots .1 .24)$ & $-17.1 \pm 13.0(-47 \ldots .0)$ & $0.49 \pm 0.20(0.22 \ldots .0 .84)$ & $-20.3 \pm 11.7(-44 \ldots .6)$ \\
\hline
\end{tabular}



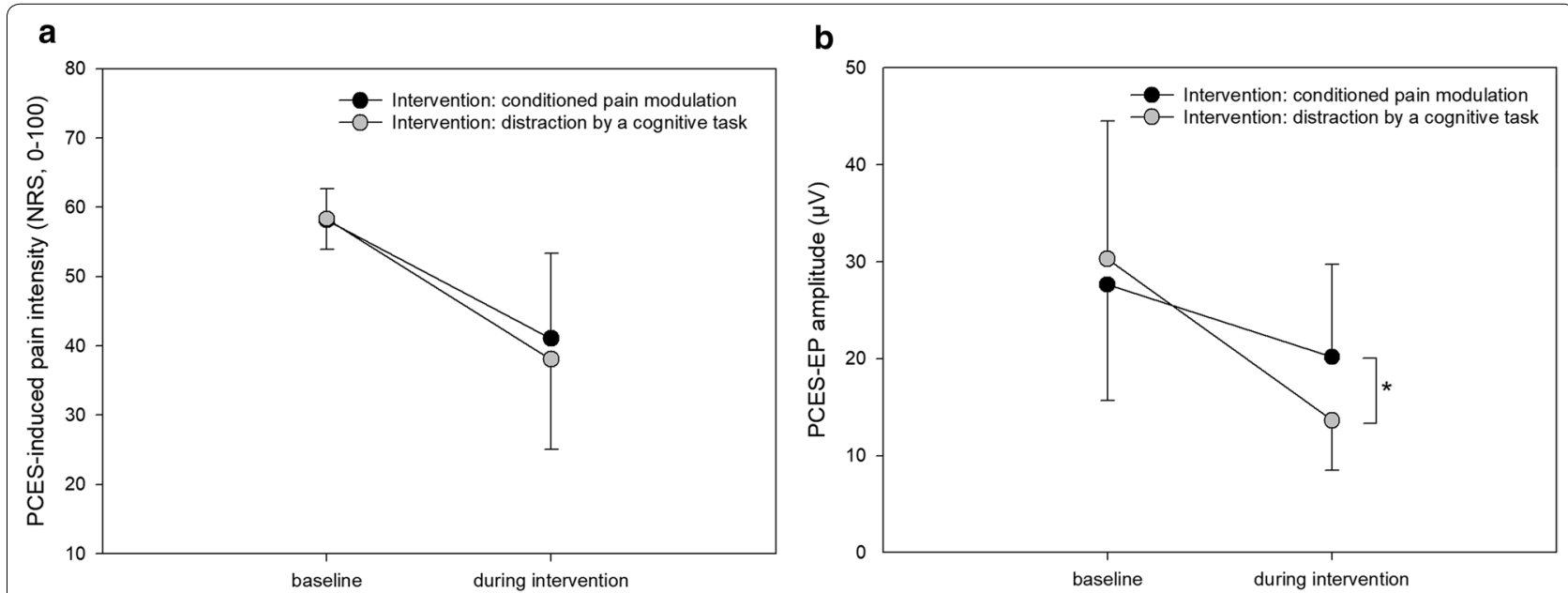

Fig. 2 Effects of conditioning pain modulation and distraction by a cognitive task on pain intensity and evoked potential after painful cutaneous electrical stimulation (PCES) at baseline and during both interventions. $\mathbf{a}$ Changes in PCES-induced pain intensity and $\mathbf{b}$ amplitudes of the evoked potential after painful cutaneous electrical stimulation (PCES-EP). Data are presented as mean \pm standard deviation. ${ }^{*} p=0.001$ for ANOVA with within factors "time" ("at baseline" and "during intervention") and "intervention" ("conditioned pain modulation" and "distraction by a cognitive task"), indicating significant interaction between "time" and "intervention"

Table 2 Repeated measures ANOVA for PCES-induced pain intensity with within factors "time" ("at baseline" and "during intervention") and "intervention" ("conditioned pain modulation" and "distraction by a cognitive task")

\begin{tabular}{llll}
\hline Within-subject factor & $\boldsymbol{F}$-value & Significance & Partial $\boldsymbol{\eta}^{\mathbf{2}}$ \\
\hline Time & $F_{1 ; 22}=127.844$ & $p<0.001$ & 0.853 \\
Intervention & $F_{1 ; 22}=0.447$ & $p=0.511$ & 0.020 \\
Time* intervention & $F_{1 ; 22}=0.662$ & $p=0.424$ & 0.029 \\
\hline
\end{tabular}

Italic values indicate significance of $p$-value $(p<0.01)$

Table 3 Repeated measures ANOVA for amplitudes of PCES-evoked potentials within factors "time" ("at baseline" and "during intervention") and "intervention" ("conditioned pain modulation" and "distraction by a cognitive task")

\begin{tabular}{llcl}
\hline Within-subject factor & F-value & Significance & Partial $\mathbf{n}^{\mathbf{2}}$ \\
\hline Time & $F_{1 ; 22}=50.362$ & $p<0.001$ & 0.696 \\
Intervention & $F_{1 ; 22}=1.077$ & $p=0.311$ & 0.047 \\
Time*intervention & $F_{1 ; 22}=13.168$ & $p=0.001$ & 0.382 \\
\hline
\end{tabular}

Italic values indicate significance of $p$-value $(p<0.01)$

during the task was $6.3 \pm 2.2$ (reported on the 11-point numerical rating scale $0-10)$. During distraction both severity grade and anger did not correlate with changes of PCES-EP amplitudes $(r=0.202, p=0.312$ and $\mathrm{r}=0.044, \mathrm{p}=0.826$, respectively) or PCES-induced

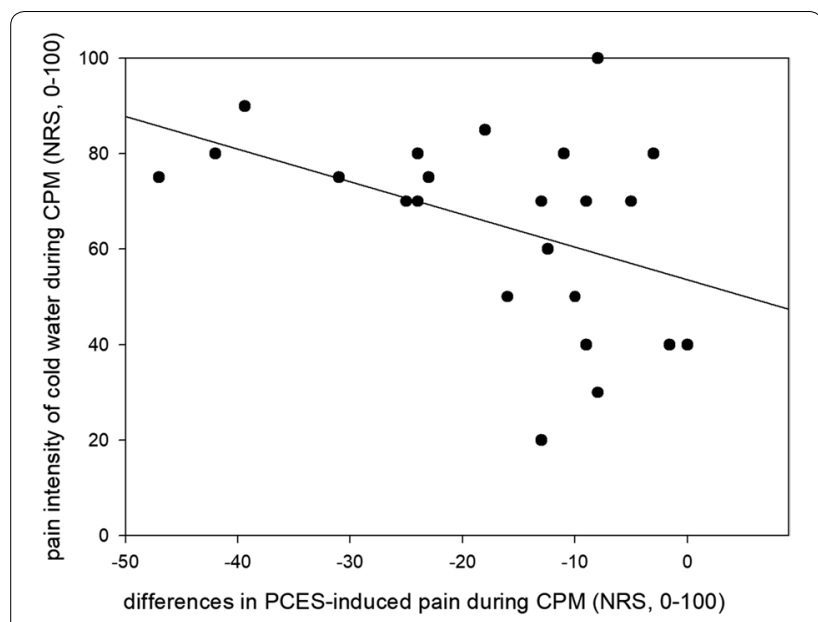

Fig. 3

pain $(\mathrm{r}=-0.153, \mathrm{p}=0.446$ and $\mathrm{r}=0.111, \mathrm{p}=0.583$, respectively).

\section{Comparison of the effects of both interventions PCES-induced pain}

ANOVA yielded a significant effect of within-subjects factor "time" on PCES-induced pain $(\mathrm{p}<0.001)$, while there was no significant effect of the within-subject factor "intervention" on PCES-induced pain (see Table 2), indicating that the PCES-induced pain reduced significantly during the intervention but the reduction of pain 
intensity did not differ between CPM and distraction (Tables 1 and 2).

\section{Amplitudes of PCES-EP}

Analyzing amplitudes of PCES-EP, the ANOVA found a significant effect of the within-subject factor "time" $(\mathrm{p}<0.001)$. Moreover, we found a significant interaction between the within-subject factors "intervention" and "time" regarding the amplitudes of PCES-EPs $(\mathrm{p}=0.001)$. This indicates that the amplitudes changed significantly during both interventions, however the changes during distraction were more pronounced than those during CPM (Tables 1 and 3).

\section{Correlations between changes during both interventions}

There was no significant correlation between the changes during CPM and distraction by a cognitive task neither regarding the PCES-induced pain $(\mathrm{r}=-0.18, \mathrm{p}=0.424)$, nor regarding the PCES-EP amplitudes $(r=0.11$, $\mathrm{p}=0.623)$.

\section{Relation between PCES-induced pain and PCES-EP amplitudes}

Changes of the PCES-induced pain (difference) and the PCES-amplitudes (ratio) correlated significantly neither during the CPM session $(\mathrm{r}=-0.32, \mathrm{p}=0.132)$ nor during the distraction session $(r=0.03, p=0.885)$.

\section{Discussion}

In summary, using the recently introduced novel CPMparadigm we demonstrated that both PCES-induced pain and PCES-EP amplitudes can be reduced not only by CPM [20,39] but also during distraction by a cognitive task. While the amount of pain relief induced by CPM and distraction by a cognitive task did not differ significantly during both interventions, the decrease of PCESEP amplitudes after distraction by a cognitive task was slightly more pronounced than during CPM. Further on, the changes during both interventions did not correlate. The latter implies that both conditions might not represent the general pain modulatory capacity of individuals, but may underlie different neuronal mechanisms, having the perceived pain reduction as final common pathway.

Focusing on the effect on pain intensity, our findings are in line with recent studies, showing that both conditioned pain modulation [14, 20,38,39] and distraction [29-33] can reduce the perceived pain intensity. Various CPM paradigms have been published using different combination of stimuli as TS and CS, for review see [47]. With PCES as TS and cold water as CS we demonstrated a reduction of pain intensity during application of CS, which was accompanied by a significant decrease of PCES-EP amplitudes similar to our previous study
[39]. The pain intensity of the cold water correlated with changes of PCES-induced pain; i. e. the more painful the conditioning stimulus was, the more pronounced it reduced the intensity of PCES-induced pain, though in contrast to the findings of our pilot study [39] the results were not significant after correction for multiple comparisons. Also, the significant correlation between pain intensity of the cold water and ratios of PCES-EP amplitudes [39] was not found in the present study. Further studies are needed to examine the influence of CSinduced pain on PCES-EPs.

Using the 1-back task, the magnitude of pain decrease in our study (on average 37\%) was well within the range of previous studies using distraction models for pain modulation such as continuous cognitive visual task, memorization task, calculations task, high tech and low tech virtual reality, where the reduction of the pain ratings ranged from 13 to $50 \%[38,48,49]$.

Interestingly, the perceived difficulty of the 1-back task did not correlate with the effect of distraction on PCESEPs and PCES-induced pain. This finding is in contrast to the above reported correlation between the intensity of CS and changes of PCES-induced pain during CPM; however, in accordance with a previous study, reporting no linear relation between the difficulty of the distraction task and the pain reduction [38]. In this study a moderate task was found to be more effective in reducing pain than a simple or difficult one. Another study reported even higher pain ratings and more pronounced spinal nociceptive responses measured by the nociceptive flexion reflex after the performance of tasks requiring high cognitive control compared to that with lower cognitive demand [50]. Nevertheless, the fact that PCES-EP amplitudes were strongly affected by distraction suggests that higher cognitive circuits are involved in the generation of the PCES-evoked cortical potentials.

Sequential CPM paradigms are a clearer representation of descending inhibition since they are less biased by distraction of the painful CS. One might argue that our CPM protocol evaluating the TS changes during a parallel CS application might not be specifically enough for assessment of the descending pain inhibition. This might be true for the changes in pain intensity, which were similar during both interventions. However, some differences must be assumed, because while the changes in pain intensity correlated only with the perceived pain intensity of the CS, though this significant result was not yielded after correction for multiple comparisons, but there was no correlation at all with the perceived difficulty of the 1-back task. Also, the missing correlation of the changes during both interventions for both pain intensity and EP-amplitudes imply that the intraindividual capacity to modulate pain differ between both 
conditions. In addition, adding a distraction task simultaneously to the CS and proofing additional reduction of pain ratings and PCES-EPs amplitudes would have been a further argument for different acting mechanisms of the two interventions. Unfortunately, this was technically not possible during the current experiments. A previous study examining CPM based on brief heat stimuli as TS and tonic heat as CS and in comparison to continuous visual cognitive distracter tasks alone and in combination demonstrated an additive effect of CPM and distraction on pain inhibition, suggesting that CPM acts independently from distraction [38].

One important limitation of our study is that fifteen subjects had to be excluded from the analysis. Ten of them were excluded due to movement artifacts that were especially observed during the CPM assessment. Interestingly, the subjects excluded due to artifacts during recordings of PCES-EP rated the pain intensity of the CS higher than those with well identifiable PCES-EP, which might have biased our results. One possible explanation could be that muscle contractions in reaction to the painfully cold water led to movement artifacts and that the ten excluded subjects presented too many artifacts because they perceived the pain induced by the CS was too strong. Thus, this subjects' group might represent subjects with generally higher pain sensitivity to cold stimuli. In conclusion, we suggest that cold water as CS should be painful enough to lead to an efficient pain inhibition/efficient CPM effect, but it should be considered for future studies using electrophysiological readouts that the more painful the CS was, the more movement artifacts due to muscular tensions occurred. Also after exclusion of subjects with artifacts in the PCES-EP recording, the studied cohort might have not been large enough to detect significant differences between the effect of conditioned pain modulation and distraction by a cognitive task. In terms of the correlations between the PCESinduced pain intensity, the amplitudes of the PCES-EPs and the intensity of the CS, further cumulative analysis of higher number of subjects are needed to further elucidate the question of a possible correlation between the differences in pain ratings (during intervention minus baseline) and the ratio of evoked potential amplitudes during conditioned pain modulation and the influence of any confounding factors.

Another possible limitation of our study was that the stimulus intensity needed to induce pain with intensity of 60 on the NRS $(0-100)$ during the second intervention was higher than during the first one. This might be well explained by a habituation effect after PCES, as we previously demonstrated that repetitive PCES leads to a moderate reduction of PCES-induced pain, thus requiring slightly stronger stimulus intensities to achieve the required pain intensity of 60 on the NRS $(0-100)$. Nevertheless, the CPM-effect was significantly larger than the effect of habituation on pain intensity and could therefore not be explained by habituation alone [20]. Furthermore, the significantly different stimulation intensity did not influence our results as we found no significant sequence effects on the outcome in the present study.

Further on, in the present study we focused on the direct comparison of painful cold water and the n-backtask and did not include control conditions for both CS, i.e. non-painful CS for CPM (e.g. immersion in $25{ }^{\circ} \mathrm{C}$ water) and passive viewing of stream of letters for cognitive task. We have recently reported significant differences between non-painful and painful CS regarding both CPM effects based on pain intensity and PCES-EP amplitudes [39], while EEG recording in combination for a control condition of the distraction task are missing. Therefore, it cannot be excluded that the somatosensory stimulation associated with immersing the hand in water (even without pain) and the visual stimulation associated with viewing letters (even without cognitive load) already modulate PCES-EP compared to a baseline PCES-EP at rest and that this modulation differs between the two conditions (somatosensory vs. visual stimulation). Thus, we cannot definitely rule out that the difference in PCESEP amplitudes reduction between CPM and cognitive distraction can be at least partially attributed to this fundamental difference between the two interventions (somatosensory vs visual stimulation).

Some authors argue that the use of the concentric electrodes to record PCES-EPs as in the present study activates not selectively the nociceptive fibers [40, 41], but are mostly related to a large myelinated fiber input. In contrast, others have demonstrated that the peak-topeak N1-P1-amplitudes assessed in a similar manner as in our study were reduced both in healthy controls and patients with neuropathic pain after application of capsaicin $8 \%$, thus being a reliable A-delta test [51]. Anyway, the question regarding the selective activation of nociceptive fibers by using concentric electrodes for electrical stimulation was not in the scope in the present study. Moreover, considering previously reported CPM paradigms using pain induced by pressure or ischemic block as TS are also based on large fiber activation, therefore this should not be a relevant limitation for the comparison between the CPM-effect and effect of distraction on pain intensity. 


\section{Conclusion}

In conclusion, our findings displayed that both CPM and distraction are effective endogenous mechanisms for reduction of PCES-induced pain but also PCESEP amplitudes. However, the even more pronounced decrease of PCES-EP amplitudes after distraction by a cognitive task and the missing correlation of the changes between both interventions imply that both conditions do not reflect the general pain modulatory capacity of individuals, but may underlie different neuronal mechanisms with the final common pathway of numerically perceived pain reduction.

Future studies recording PCES-EP not only above $\mathrm{Cz}$ but multi-segmentally at different levels of the afferent pathway (peripheral, spinal, cortical) and foot immersion as CS for heterosegmental activation or including also functional imaging might further elucidate the differences of their neural circuits.

\begin{abstract}
Abbreviations
CPM: Conditioned pain modulation; TS: Test stimulus; CS: Contact stimulus: PCES: Painful cutaneous electrical stimulation; EP: Evoked potentials; PCESEP: Evoked potentials after painful cutaneous electrical stimulation; fMRI: Functional magnetic resonance imaging; DT: Detection threshold; PT: Pain thresholds; NRS: Numerical rating scale.
\end{abstract}

\section{Acknowledgements}

We thank all subjects who participated into the study. This work is part of the doctoral thesis of Anh Thuy Lisa Do.

\begin{abstract}
Authors' contributions
EKEK, ÖÖ, LBE, MT, CM and OH have made substantial contributions to the conception or design of the work. ATLD, EKEK, LE, SB, ÖÖ were involved in the acquisition, analysis, or interpretation of data. ATLDLD, EKEK and OH have drafted the manuscript and the tables and figures or substantively revised it. All authors have approved the submitted version and have agreed both to be personally accountable for the author's own contributions and to ensure that questions related to the accuracy or integrity of any part of the work, even ones in which the author was not personally involved, are appropriately investigated, resolved, and the resolution documented in the literature. All authors read and approved the final manuscript.
\end{abstract}

\section{Funding}

Open Access funding enabled and organized by Projekt DEAL.. This work was supported by the Deutsche Forschungsgemeinschaft, SFB 874/A1 and A5, Project No.: 122679504 . E. E.-K. holds an endowed professorships funded by the German Social Accident Insurance (DGUV) for the time of 6 years (20202026). Ö.Ö. received intramural fundings from the Ruhr University Bochum (FoRUM grant number K120-18). L.B. E. received intramural funding from the Ruhr University Bochum, Germany (FoRUM Grant Number K135-19).

\section{Availability of data and materials}

The datasets used and/or analyzed during the current study are available from the corresponding author on reasonable request.

\section{Ethics approval and consent to participate}

The study was approved by the Ethics Committee of the Medical Faculty of the Ruhr University Bochum, Germany under the registration number 16-5733, participation into the study was only after written informed consent.

\section{Consent for publication}

Not applicable.

\section{Competing interests}

The authors declare that they have no competing interests.

\section{Author details}

${ }^{1}$ Department of Neurology, Ruhr-University Bochum, BG University Hospital Bergmannsheil gGmbH, Bürkle-de-la-Camp-Platz 1, 44789 Bochum, Germany. ${ }^{2}$ Department of Pain Medicine, Ruhr-University Bochum, BG University Hospital Bergmannsheil gGmbH, Bürkle-de-la-Camp-Platz 1, 44789 Bochum, Germany. ${ }^{3}$ Department of Neuropaediatrics, University Children's Hospital, Ruhr-University Bochum, Alexandrinenstraße 5, 44791 Bochum, Germany.

Received: 30 April 2020 Accepted: 23 November 2020

Published online: 07 December 2020

\section{References}

1. Damien J, Colloca L, Bellei-Rodriguez CE, Marchand S. Pain modulation: from conditioned pain modulation to placebo and nocebo effects in experimental and clinical pain. Int Rev Neurobiol. 2018;139:255-96. https ://doi.org/10.1016/bs.irn.2018.07.024.

2. Yarnitsky D. Role of endogenous pain modulation in chronic pain mechanisms and treatment. Pain. 2015;156(Suppl 1):S24-31. https://doi. org/10.1097/01.j.pain.0000460343.46847.58.

3. Edwards RR, Ness TJ, Weigent DA, Fillingim RB. Individual differences in diffuse noxious inhibitory controls (DNIC): association with clinical variables. Pain. 2003;106:427-37.

4. Daenen $L$, et al. Dysfunctional pain inhibition in patients with chronic whiplash-associated disorders: an experimental study. Clin Rheumatol. 2013;32:23-31. https://doi.org/10.1007/s10067-012-2085-2.

5. Lewis GN, Rice DA, McNair PJ. Conditioned pain modulation in populations with chronic pain: a systematic review and meta-analysis. J Pain. 2012;13:936-44. https://doi.org/10.1016/j.jpain.2012.07.005.

6. Grosen K, Vase L, Pilegaard HK, Pfeiffer-Jensen M, Drewes AM. Conditioned pain modulation and situational pain catastrophizing as preoperative predictors of pain following chest wall surgery: a prospective observational cohort study. PLoS ONE. 2014;9:e90185. https://doi.org/10.1371/ journal.pone.0090185.

7. Petersen KK, Graven-Nielsen T, Simonsen O, Laursen MB, Arendt-Nielsen L. Preoperative pain mechanisms assessed by cuff algometry are associated with chronic postoperative pain relief after total knee replacement. Pain. 2016;157:1400-6. https://doi.org/10.1097/j.pain.0000000000000531.

8. Yarnitsky D, et al. Prediction of chronic post-operative pain: pre-operative DNIC testing identifies patients at risk. Pain. 2008;138:22-8. https://doi. org/10.1016/j.pain.2007.10.033.

9. Bingel U, Lorenz J, Schoell E, Weiller C, Buchel C. Mechanisms of placebo analgesia: RACC recruitment of a subcortical antinociceptive network. Pain. 2006;120:8-15. https://doi.org/10.1016/j.pain.2005.08.027.

10. Lorenz J, Minoshima S, Casey KL. Keeping pain out of mind: the role of the dorsolateral prefrontal cortex in pain modulation. Brain. 2003;126:1079-91. https://doi.org/10.1093/brain/awg 102.

11. Ohara PT, Vit JP, Jasmin L. Cortical modulation of pain. Cell Mol Life Sci. 2005;62:44-52. https://doi.org/10.1007/s00018-004-4283-9.

12. Petrovic $P$, Ingvar $M$. Imaging cognitive modulation of pain processing. Pain. 2002;95:1-5.

13. Bogdanov VB, et al. Cerebral responses and role of the prefrontal cortex in conditioned pain modulation: an fMRI study in healthy subjects. Behav Brain Res. 2015;281:187-98. https://doi.org/10.1016/j.bbr.2014.11.028.

14. Moont R, Crispel Y, Lev R, Pud D, Yarnitsky D. Temporal changes in cortical activation during conditioned pain modulation (CPM), a LORETA study. Pain. 2011;152:1469-77. https://doi.org/10.1016/j.pain.2011.01.036.

15. Youssef AM, Macefield VG, Henderson LA. Pain inhibits pain; human brainstem mechanisms. Neuroimage. 2016;124:54-62. https://doi. org/10.1016/j.neuroimage.2015.08.060.

16. Cadden SW, Villanueva L, Chitour D, Le Bars D. Depression of activities of dorsal horn convergent neurones by propriospinal mechanisms triggered by noxious inputs; comparison with diffuse noxious inhibitory controls (DNIC). Brain Res. 1983;275:1-11. https://doi.org/10.1016/00068993(83)90412-2. 
17. Le Bars D, Dickenson AH, Besson JM. Diffuse noxious inhibitory controls (DNIC). I. Effects on dorsal horn convergent neurones in the rat. Pain. 1979;6:283-304.

18. Cadden SW, Newton JP. The effects of inhibitory controls triggered by heterotopic noxious stimuli on a jaw reflex evoked by perioral stimuli in man. Arch Oral Biol. 1994;39:473-80.

19. Edwards RR, Fillingim RB, Ness TJ. Age-related differences in endogenous pain modulation: a comparison of diffuse noxious inhibitory controls in healthy older and younger adults. Pain. 2003;101:155-65.

20. Eitner $L$, et al. Conditioned pain modulation using painful cutaneous electrical stimulation or simply habituation? Eur J Pain. 2018;22:1281-90. https://doi.org/10.1002/ejp.1215.

21. Granot $M$, et al. Determinants of endogenous analgesia magnitude in a diffuse noxious inhibitory control (DNIC) paradigm: do conditioning stimulus painfulness, gender and personality variables matter? Pain. 2008;136:142-9. https://doi.org/10.1016/j.pain.2007.06.029.

22. Pud D, Granovsky Y, Yarnitsky D. The methodology of experimentally induced diffuse noxious inhibitory control (DNIC)-like effect in humans. Pain. 2009;144:16-9. https://doi.org/10.1016/j.pain.2009.02.015.

23. Pud D, Sprecher E, Yarnitsky D. Homotopic and heterotopic effects of endogenous analgesia in healthy volunteers. Neurosci Lett. 2005;380:209-13. https://doi.org/10.1016/j.neulet.2005.01.037.

24. Staud R, Robinson ME, Vierck CJ Jr, Price DD. Diffuse noxious inhibitory controls (DNIC) attenuate temporal summation of second pain in normal males but not in normal females or fibromyalgia patients. Pain. 2003;101:167-74. https://doi.org/10.1016/s0304-3959(02)00325-1.

25. Lautenbacher S, Prager M, Rollman GB. Pain additivity, diffuse noxious inhibitory controls, and attention: a functional measurement analysis. Somatosens Mot Res. 2007;24:189-201. https://doi.org/10.1080/08990 220701637638.

26. Vaegter HB, Fehrmann $E_{,}$Gajsar $H$, Kreddig N. Endogenous modulation of pain: the role of exercise, stress, and cognitions in humans. Clin J Pain. 2020:36:150-61. https://doi.org/10.1097/AJP.0000000000000788.

27. Volz MS, Suarez-Contreras V, Portilla AL, Fregni F. Mental imagery-induced attention modulates pain perception and cortical excitability. BMC Neurosci. 2015;16:15. https://doi.org/10.1186/s12868-015-0146-6.

28. Villemure C, Bushnell MC. Cognitive modulation of pain: how do attention and emotion influence pain processing? Pain. 2002;95:195-9.

29. Calcaterra $V$, et al. Music benefits on postoperative distress and pain in pediatric day care surgery. Pediatr Rep. 2014;6:5534. https://doi. org/10.4081/pr.2014.5534.

30. Good M, et al. Pain after gynecologic surgery. Pain Manag Nurs. 2000;1:96-104. https://doi.org/10.1053/jpmn.2000.9857.

31. Good M, et al. Relief of postoperative pain with jaw relaxation, music and their combination. Pain. 1999;81:163-72.

32. He HG, et al. Therapeutic play intervention on children's perioperative anxiety, negative emotional manifestation and postoperative pain: a randomized controlled trial. J Adv Nurs. 2015;71:1032-43. https://doi. org/10.1111/jan.12608.

33. Calcaterra V, et al. Post-operative benefits of animal-assisted therapy in pediatric surgery: a randomised study. PLoS ONE. 2015;10:e0125813. https://doi.org/10.1371/journal.pone.0125813.

34. Kirchner WK. Age differences in short-term retention of rapidly changing information. J Exp Psychol. 1958;55:352-8.
35. Lavie N. Distracted and confused?: selective attention under load. Trends Cogn Sci. 2005;9:75-82. https://doi.org/10.1016/j.tics.2004.12.004.

36. Lorenz J, Bromm B. Event-related potential correlates of interference between cognitive performance and tonic experimental pain. Psychophysiology. 1997:34:436-45.

37. Obermann $\mathrm{M}$, et al. Temporal summation of trigeminal pain in human anterior cingulate cortex. Neuroimage. 2009;46:193-200. https://doi. org/10.1016/j.neuroimage.2009.01.038.

38. Moont R, Pud D, Sprecher E, Sharvit G, Yarnitsky D. "Pain inhibits pain" mechanisms: Is pain modulation simply due to distraction? Pain. 2010;150:113-20. https://doi.org/10.1016/j.pain.2010.04.009.

39. Hoffken O, Ozgul OS, Enax-Krumova EK, Tegenthoff M, Maier C. Evoked potentials after painful cutaneous electrical stimulation depict pain relief during a conditioned pain modulation. BMC Neurol. 2017;17:167. https:// doi.org/10.1186/s12883-017-0946-7.

40. Buhle J, Wager TD. Performance-dependent inhibition of pain by an executive working memory task. Pain. 2010;149:19-26. https://doi. org/10.1016/j.pain.2009.10.027.

41. 41 Coen SJ et al. Effects of attention on visceral stimulus intensity encoding in the male human brain. Gastroenterology. 2008; 135: 2065-2074, 2074 e2061, doi:https://doi.org/10.1053/j.gastro.2008.08.005.

42. Sprenger $C$, et al. Attention modulates spinal cord responses to pain. Curr Biol. 2012;22:1019-22. https://doi.org/10.1016/j.cub.2012.04.006.

43. Katsarava Z, et al. A novel method of eliciting pain-related potentials by transcutaneous electrical stimulation. Headache. 2006;46:1511-7. https:// doi.org/10.1111/j.1526-4610.2006.00446.x.

44. Oh KJ, et al. Pain-related evoked potential in healthy adults. Ann Rehabil Med. 2015;39:108-15. https://doi.org/10.5535/arm.2015.39.1.108.

45. Yarnitsky D, Granot M, Nahman-Averbuch H, Khamaisi M, Granovsky Y. Conditioned pain modulation predicts duloxetine efficacy in painful diabetic neuropathy. Pain. 2012;153:1193-8. https://doi.org/10.1016/j. pain.2012.02.021.

46. Wellek S, Blettner M. On the proper use of the crossover design in clinical trials: part 18 of a series on evaluation of scientific publications. Dtsch Arztebl Int. 2012;109:276-81. https://doi.org/10.3238/arztebl.2012.0276.

47. Nir RR, Yarnitsky D. Conditioned pain modulation. Curr Opin Support Palliat Care. 2015;9:131-7. https://doi.org/10.1097/SPC.0000000000000126.

48. Hoffman $\mathrm{HG}$, et al. Manipulating presence influences the magnitude of virtual reality analgesia. Pain. 2004;111:162-8. https://doi.org/10.1016/j. pain.2004.06.013.

49. Yamasaki H, Kakigi R, Watanabe S, Hoshiyama M. Effects of distraction on pain-related somatosensory evoked magnetic fields and potentials following painful electrical stimulation. Brain Res Cogn Brain Res. 2000;9:165-75.

50. Silvestrini N, Rainville P. After-effects of cognitive control on pain. Eur J Pain. 2013;17:1225-33. https://doi.org/10.1002/j.1532-2149.2013.00299.x.

51. Papagianni A, Siedler G, Sommer C, Uceyler N. Capsaicin $8 \%$ patch reversibly reduces A-delta fiber evoked potential amplitudes. Pain Rep. 2018;3:e644. https://doi.org/10.1097/PR9.0000000000000644.

\section{Publisher's Note}

Springer Nature remains neutral with regard to jurisdictional claims in published maps and institutional affiliations.
Ready to submit your research? Choose BMC and benefit from:

- fast, convenient online submission

- thorough peer review by experienced researchers in your field

- rapid publication on acceptance

- support for research data, including large and complex data types

- gold Open Access which fosters wider collaboration and increased citations

- maximum visibility for your research: over $100 \mathrm{M}$ website views per year

At BMC, research is always in progress.

Learn more biomedcentral.com/submissions 